Article

\title{
Sustainable solid-state synthesis of uniformly distributed PdAg alloy nanoparticles for electrocatalytic hydrogen oxidation and evolution
}

\author{
Caili Xu a, Qian Chen a, Rong Ding a, Shengtian Huang b, Yun Zhang a,*, Guangyin Fan a,\# \\ a College of Chemistry and Materials Science, Sichuan Normal University, Chengdu 610068, Sichuan, China \\ ${ }^{\mathrm{b}}$ Key Laboratory of Green Catalysis of Higher Education Institutes of Sichuan, College of Chemistry and Environment Engineering, Sichuan University of \\ Science and Engineering, Zigong 643000, Sichuan, China
}

\section{A R T I C L E I N F O}

\section{Article history:}

Received 31 March 2020

Accepted 7 May 2020

Published 5 February 2021

\section{Keywords:}

Solid-state synthesis

Supported metallic alloy nanoparticles

Electrocatalysis

Hydrogen oxidation reaction

Hydrogen evolution reaction

\begin{abstract}
A B S T R A C T
New sustainable syntheses based on solid-state strategies have sparked enormous attention and provided novel routes for the synthesis of supported metallic alloy nanocatalysts (SMACs). Despite considerable recent progress in this field, most of the developed methods suffer from either complex operations or poorly controlled morphology, which seriously limits their practical applications. Here, we have developed a sustainable strategy for the synthesis of PdAg alloy nanoparticles (NPs) with an ultrafine size and good dispersion on various carbon matrices by directly grinding the precursors in an agate mortar at room temperature. Interestingly, no solvents or organic reagents are used in the synthesis procedure. This simple and green synthesis procedure provides alloy NPs with clean surfaces and thus an abundance of accessible active sites. Based on the combination of this property and the synergistic and alloy effects between Pd and Ag atoms, which endow the NPs with high intrinsic activity, the $\mathrm{PdAg} / \mathrm{C}$ samples exhibit excellent activities as electrocatalysts for both the hydrogen oxidation and evolution reactions (HOR and HER) in a basic medium. $\mathrm{Pd}_{9} \mathrm{Ag}_{1} / \mathrm{C}$ showed the highest activity in the HOR with the largest $j_{0, \mathrm{~m}}$ value of $26.5 \mathrm{~A} \mathrm{~g}_{\mathrm{Pd}^{-1}}$ and $j_{0, s}$ value of $0.033 \mathrm{~mA}$ $\mathrm{cm}_{\mathrm{Pd}^{-}}{ }^{2}$, as well as in the HER, with the lowest overpotential of $68 \mathrm{mV}$ at $10 \mathrm{~mA} \mathrm{~cm}{ }^{-2}$. As this synthetic method can be easily adapted to other systems, the present scalable solid-state strategy may open opportunity for the general synthesis of a wide range of well-defined SMACs for diverse applications.
\end{abstract}

(C) 2021, Dalian Institute of Chemical Physics, Chinese Academy of Sciences. Published by Elsevier B.V. All rights reserved.

\section{Introduction}

Supported metallic alloy nanocatalysts (SMACs) have sparked tremendous interest in industry and fundamental research due to their high intrinsic activity, stability, and recyclability. For example, SMACs have been widely applied in the fields of thermal and electrochemical catalysis [1-3]. In particular, alloying two metals enable tailoring of their electronic or/and geometric structures and can induce a synergetic catalysis effect, thus enhancing the intrinsic activity of the active sites or/and modifying the reaction routes to speed the reactions $[4,5]$. Additionally, reducing the size of alloyed nanoparticles (NPs) and improving their dispersion on supports can endow SMACs with a larger number of accessible sites, which guarantees the presence of sufficient active centers for catalytic reactions. However, the high surface energy of NPs and the

\footnotetext{
* Corresponding author. Tel/Fax: +86-28-84760802; E-mail: zhangyun@sicnu.edu.cn

\# Corresponding author. E-mail: fanguangyin@sicnu.edu.cn

This work was supported by the National Natural Science Foundation of China (21905187, 21777109) and the Key Laboratory of Green Catalysis of Higher Education Institutes of Sichuan (LZJ1802).

DOI: 10.1016/S1872-2067(20)63650-6 | http://www.sciencedirect.com/science/journal/18722067 | Chin. J. Catal., Vol. 42 , No. 2, February 2021
} 
difficulty of alloying metals with different physical/chemical properties often result in severe aggregation and inhomogeneous alloying of NPs. Consequently, the development of efficient strategies to produce small-sized, well-dispersed alloy NPs for SMACs is of considerable importance.

In recent years, various solution-based strategies to produce SMACs, including co-precipitation, impregnation, and solvothermal/hydrothermal methods, have been widely explored [6-8]. To effectively control the size and avoid the potential agglomeration of alloy NPs, large amounts of organic agents (e.g., organic solvents, surfactants, and capping agents) were generally and largely introduced in the synthesis procedures. However, this makes the entire process cost-ineffective, complicated, and environmentally unfriendly; thus, SMACs produced in this manner are unfavorable for large-scale applications. Moreover, the organic agents, especially surfactants, are likely to be strongly adsorbed on the surface of the alloy NPs, thus decreasing their catalytic surface areas. The extra steps required to remove these ligands unavoidably cause sintering of the alloy NPs, which decreases their active surface areas and amount of accessible active sites for catalytic applications.

To overcome these drawbacks, solid-state strategies have been explored as alternative methods to produce SMACs in recent years. The typical solid-state strategy of high temperature pyrolysis has been employed to produce many types of SMACs; however, control of the morphology and size of the alloy NPs is very difficult at high temperature because of their high surface energy. To achieve morphological control and limit overgrowth of the alloy NPs, the pyrolysis must be completed within a short reaction time using special heating equipment [9]. In light of these drawbacks, the use of mortar-pestle milling for the synthesis of NPs has attracted considerable attention, as this method can be carried out under normal ambient conditions and can eliminate or dramatically reduce the usage of hazardous organic agents [10-13]. However, to date, strategies for the synthesis of small-sized alloy NPs that are uniform dispersed on matrices via mortar-pestle milling have rarely been reported, and remain a great challenge.

Herein, a series of carbon-supported PdAg alloy NPs were produced using a mechanochemically assisted strategy involving the direct mortar-pestle milling of the precursors in an agate mortar at room temperature. The resulting PdAg alloy NPs exhibited a small size and clean surfaces and were highly and uniformly distributed on a carbon matrix, thus providing abundant accessible active sites. By adjusting the atomic ratio of Pd and Ag through tuning the amounts of the precursors, the optimal positive synergistic and alloy effects were easily realized to produce PdAg alloy NPs with a high intrinsic activity. Because of these features, the resulting PdAg/C electrocatalysts showed excellent activities for the hydrogen oxidation and evolution reactions (HOR, HER) in an alkaline medium. Notably, neither the size nor the dispersion of the alloy NPs was influenced by the topological structure of the carbon support, and thus, their use could be extended to most nanocarbons, including super $\mathrm{P}, 3 \mathrm{D}$ graphene, and self-prepared 3D porous carbon. The developed strategy was quite simple, time-efficient, and environmentally friendly, and thus represents a new way to produce ultrafine and highly-dispersed alloy NPs on matrices for various catalytic applications.

\section{Experimental}

A series of carbon-supported PdAg alloy NPs were synthesized by directly grinding the precursors in an agate mortar at room temperature. Please see more details in the Supporting Information.

\section{Results and discussion}

The procedure for the synthesis of $\mathrm{PdAg} / \mathrm{C}$ via the mechanochemically assisted strategy involving mortar-pestle milling is illustrated in Fig. 1. In a typical synthesis, the metal precursors (palladium chloride and silver nitrate) were uniformly mixed with carbon black, sodium hydroxide $(\mathrm{NaOH})$, and sodium borohydride $\left(\mathrm{NaBH}_{4}\right)$ via mortar-pestle milling. With the assistance of $\mathrm{NaOH}$, the metal precursors were gradually reduced by $\mathrm{NaBH}_{4}$ to form PdAg alloy NPs, which were loaded on the carbon support in significant amounts. The final products were easily obtained after the removal of impurities via rinsing with water. The carbon-supported PdAg alloy products with different molar ratios of $\mathrm{Pd} / \mathrm{Ag}$ were denoted as $\mathrm{Pd} / \mathrm{C}$, $\mathrm{Pd}_{9} \mathrm{Ag}_{1} / \mathrm{C}, \mathrm{Pd}_{5} \mathrm{Ag}_{5} / \mathrm{C}, \mathrm{Pd}_{1} \mathrm{Ag}_{9} / \mathrm{C}$, and $\mathrm{Ag} / \mathrm{C}$, respectively.

The morphologies of the $\mathrm{PdAg} / \mathrm{C}$ and reference samples were first analyzed using transmission electron microscopy (TEM). As shown in Figs. 2(a)-(d) and 3(a),(b), the dispersion of NPs gradually improved with increasing Ag content, and the NPs of $\mathrm{Pd}_{5} \mathrm{Ag}_{5} / \mathrm{C}$ showed the best dispersion. Further increasing the Ag content led to deterioration of the dispersion of the NPs. The corresponding bar graphs reveal that the NPs of Pd/C, $\mathrm{Pd}_{9} \mathrm{Ag}_{1} / \mathrm{C}, \mathrm{Pd}_{5} \mathrm{Ag}_{5} / \mathrm{C}, \mathrm{Pd}_{1} \mathrm{Ag}_{9} / \mathrm{C}$, and $\mathrm{Ag} / \mathrm{C}$ had average sizes of 4.8, 5.3, 4.9, 4.5, and $4.7 \mathrm{~nm}$, respectively (Figs. 2(e)-(h) and 3 (c)). These results indicated that the composition of the NPs had a negligible influence on their size. The fringe spacings for the NPs of $\mathrm{Pd} / \mathrm{C}$ and $\mathrm{Ag} / \mathrm{C}$ can clearly be distinguished in the insets of Fig. 2(a),(d), and were indexed to the (111) plane of metallic $\mathrm{Pd}$ and $\mathrm{Ag}$, respectively. The lattice spacings in the insets of Figs. 2(b),(c) and 3(b) were measured to be 0.230 , 0.233 , and $0.231 \mathrm{~nm}$, respectively, all of which were intermediates between the lattice spacings of the (111) plane of metallic Ag (0.24 nm) and Pd (0.22 nm), indicating successful PdAg

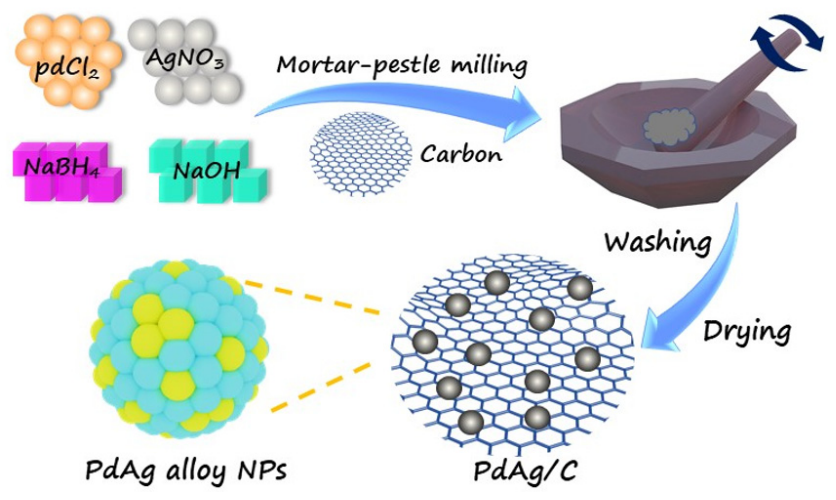

Fig. 1. Schematic illustration of the synthesis of $\mathrm{PdAg} / \mathrm{C}$. 


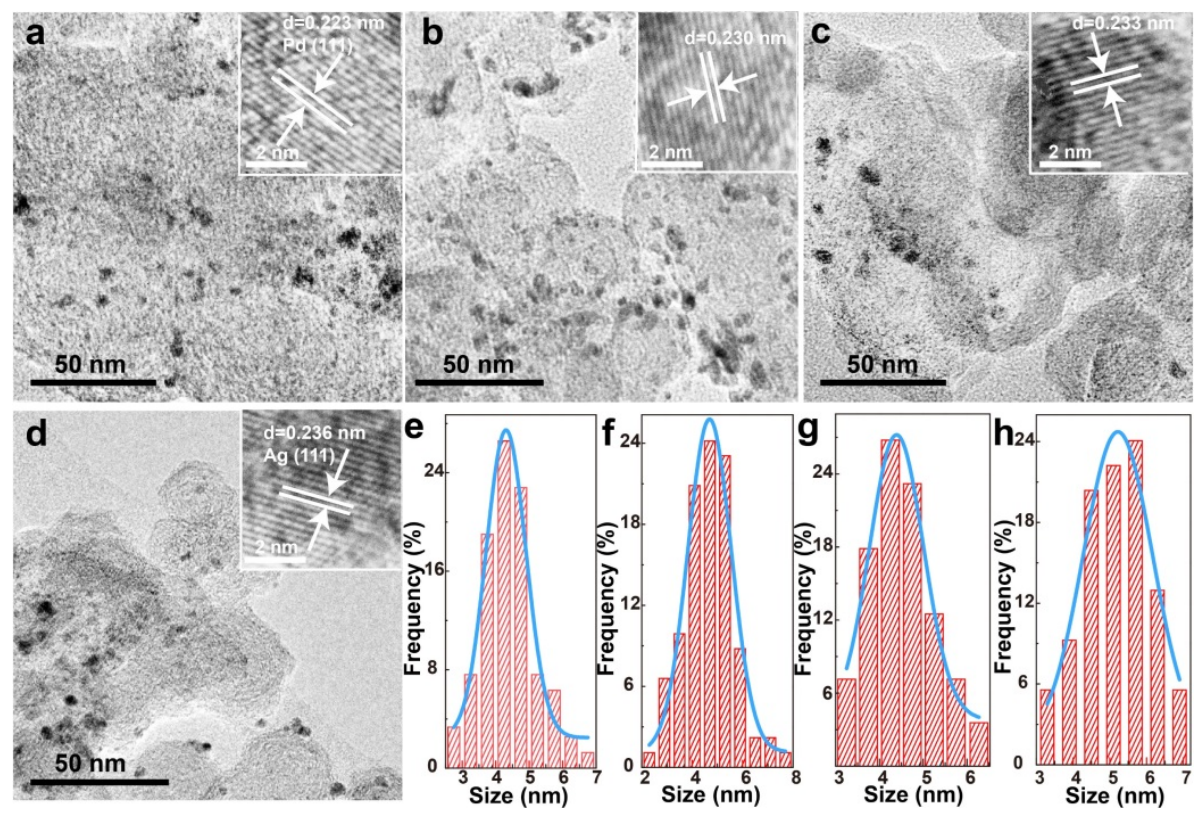

Fig. 2. TEM images and particle size distributions of $\mathrm{Pd} / \mathrm{C}(\mathrm{a}, \mathrm{e}), \mathrm{Pd}_{9} \mathrm{Ag}_{1} / \mathrm{C}(\mathrm{b}, \mathrm{f}), \mathrm{Pd}_{1} \mathrm{Ag}_{9} / \mathrm{C}(\mathrm{c}, \mathrm{g})$, and $\mathrm{Ag} / \mathrm{C}(\mathrm{d}, \mathrm{h})$. Insets in a-d are the HRTEM images of the corresponding NPs.

alloying in the $\mathrm{Pd}_{9} \mathrm{Ag}_{1} / \mathrm{C}, \mathrm{Pd}_{5} \mathrm{Ag}_{5} / \mathrm{C}$, and $\mathrm{Pd}_{1} \mathrm{Ag}_{9} / \mathrm{C}$ samples $[14,15]$. As a typical sample, $\mathrm{Pd}_{5} \mathrm{Ag}_{5} / \mathrm{C}$ was further analyzed using scanning TEM (STEM) and the energy-dispersive spectrometry (EDS) mapping technique. As shown in Fig. 3(d)-(g), the elements Pd and Ag were finely distributed across the carbon matrix. Based on the above results, it can reasonably be concluded that PdAg alloy NPs with an ultrafine size and high dispersion on the carbon matrix were successfully synthesized via our developed mortar-pestle grinding strategy, and that

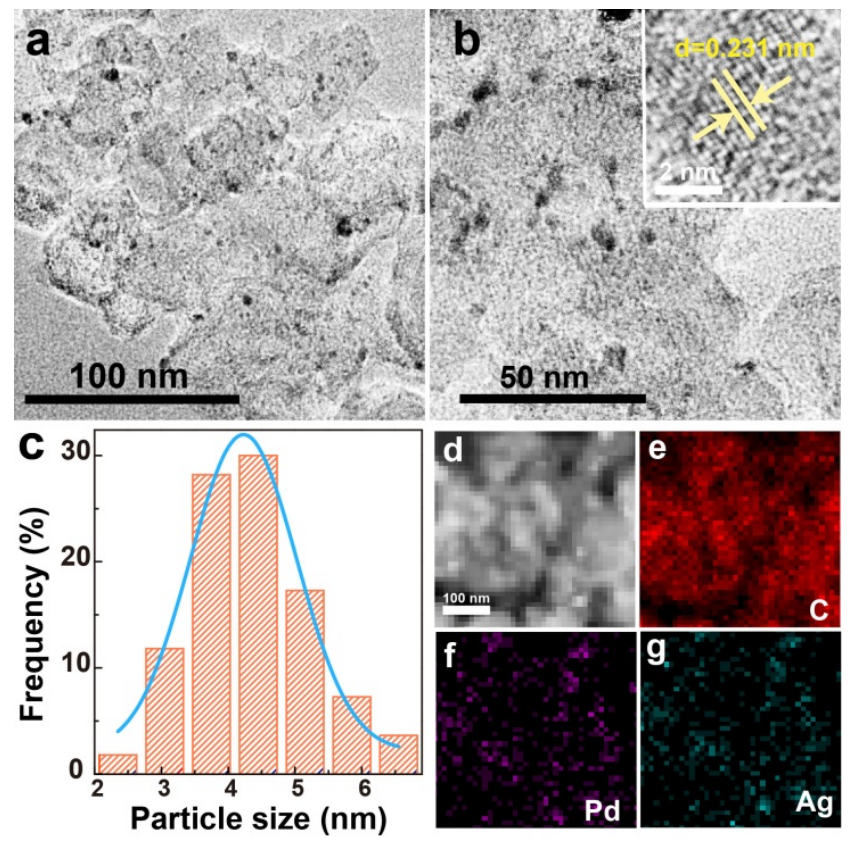

Fig. 3. (a, b) TEM images of $\mathrm{Pd}_{5} \mathrm{Ag}_{5} / \mathrm{C}$ (Inset in $\mathrm{b}$ is the HRTEM image of the corresponding NPs); (c) Corresponding particle size distribution; STEM (d) and EDS mapping images (e-g) of $\mathrm{Pd}_{5} \mathrm{Ag}_{5} / \mathrm{C}$ : (e) C, (f) Pd, and (g) Ag. their composition could be tuned by simply adjusting the molar ratio of the precursors.

The chemical composition and crystal structure of the $\mathrm{PdAg} / \mathrm{C}$ and reference samples were characterized using X-ray diffraction (XRD); the results are shown in Figs. 4(a) and S1. In addition to the two characteristic peaks of the carbon matrix at $24.6^{\circ}$ and $44.1^{\circ}$, several intense diffraction peaks corresponding to Pd, PdAg, or Ag NPs were clearly observed. The diffraction peaks at $40.12^{\circ}, 46.66^{\circ}$, and $68.12^{\circ}$ in the $\mathrm{Pd} / \mathrm{C}$ sample
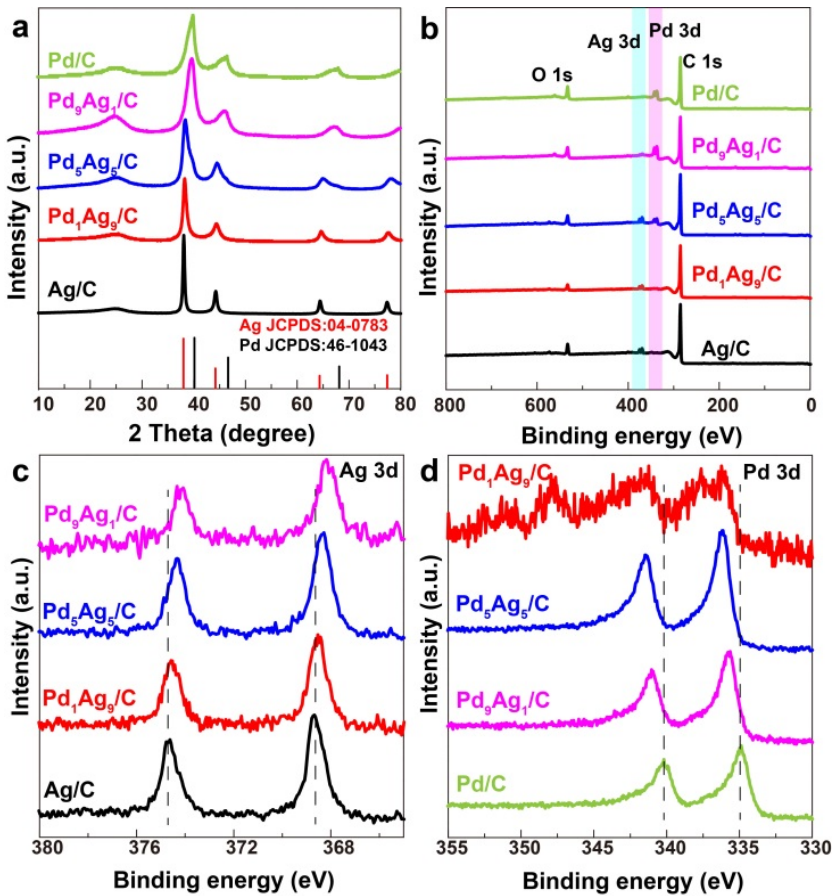

Fig. 4. XRD patterns (a), XPS survey spectra (b), Ag $3 d$ (c), and Pd $3 d$ (d) XPS spectra of the as-prepared and reference samples. 
corresponded well with the (111), (200), and (220) planes of Pd metal (JCPDS No. 46-1043), respectively. The characteristic peaks at $38.12^{\circ}, 44.28^{\circ}$, and $64.43^{\circ}$ detected in the $\mathrm{Ag} / \mathrm{C}$ sample were ascribed to the (111), (200), and (220) planes of Ag metal (JCPDS No. 04-0783), respectively. For the alloy samples, the main peaks shifted slightly toward higher angle compared to those of Ag metal, which can be mainly attributed to the alloy effect [16]. Since the atomic radius of Pd (137 pm) is smaller than that of Ag (144 pm), shrinkage of the nanoalloyed phase would be expected to occur with increasing Pd content, which would cause the peaks of the XRD patterns shift to a higher angle $[17,18]$. These results again indicated that PdAg alloy NPs were successfully prepared via our developed mortar-pestle grinding strategy, in agreement with the TEM observations.

X-ray photoelectron spectroscopy (XPS) was employed to characterize the surface composition and chemical states of the $\mathrm{PdAg} / \mathrm{C}$ and reference samples. Fig. 4(b) shows the XPS survey spectra. Only the elements $\mathrm{Pd}$ and $\mathrm{C}$ or $\mathrm{Ag}$ and $\mathrm{C}$ were detected in $\mathrm{Pd} / \mathrm{C}$ and $\mathrm{Ag} / \mathrm{C}$, respectively, whereas $\mathrm{Pd}, \mathrm{Ag}$, and $\mathrm{C}$ were clearly observed in the $\mathrm{Pd}_{9} \mathrm{Ag}_{1} / \mathrm{C}, \mathrm{Pd}_{5} \mathrm{Ag}_{5} / \mathrm{C}$, and $\mathrm{Pd}_{1} \mathrm{Ag}_{9} / \mathrm{C}$ samples, indicating the successful fabrication of bimetallic samples. Fig. 4(c) and (d) show the Ag $3 d$ and Pd $3 d$ core level spectra. Compared to those in the $\mathrm{Ag} / \mathrm{C}$ spectrum, the $\mathrm{Ag} 3 d$ core-level peaks were clearly shifted to lower binding energies in the three alloy samples. The magnitude of this shift became greater with increasing Pd content (Fig. 4(c)). In the Pd 3d XPS spectra, however, the binding energies of three alloy samples were shifted to higher binding energy compared to those of Pd/C (Fig. 4(d)), with the Pd 3d binding energy becoming more positive with increasing $\mathrm{Ag}$ content. The effect of negatively charged Ag and positively charged Pd in the PdAg alloy were in good agreement with previous reports in the literature, which attribute this phenomenon to the $d$-band overlap of Pd and $\mathrm{Ag}$ atoms, and, thus, electron transfer from Pd to Ag [19-21]. These results again demonstrated the successful preparation of PdAg alloy NPs via our developed mortar-pestle milling strategy.

To understand the mechanism by which the small-sized, highly dispersed PdAg alloy was formed during the mortar-pestle milling, a control sample was synthesized using the same procedure as for $\mathrm{Pd}_{5} \mathrm{Ag}_{5} / \mathrm{C}$, except that $\mathrm{NaOH}$ was not added. Notably, large-sized NPs $(9.74 \mathrm{~nm})$ with some aggregation were detected on the carbon matrix, as demonstrated by their TEM images and XRD patterns (Figs. S2 and S3). The corresponding HRTEM image shows a crystalline lattice fringe with a lattice spacing of $0.231 \mathrm{~nm}$, confirming the successful formation of the PdAg alloy NPs. These results indicated that the addition of $\mathrm{NaOH}$ during the synthetic process played a critical role in controlling the size of the PdAg alloy NPs rather than affecting their crystal structure. The importance of $\mathrm{NaOH}$ in the synthetic process was ascribed to the following factors: (1) Metal ions often coordinate with $\mathrm{OH}^{-}$to form mixed $\mathrm{M}-\mathrm{OH}$ intermediates with reduced redox potentials, which thus retard the redox reaction rate between the $\mathrm{M}-\mathrm{OH}$ intermediates and $\mathrm{NaBH}_{4}$, leading to the formation of small-sized PdAg alloy NPs on the carbon matrix $[10,22]$. (2) $\mathrm{NaOH}$ can also activate the carbon matrix during the mortar-pestle milling, endowing the carbon matrix with abundant oxygen-based groups, e.g., $\mathrm{C}=\mathrm{O}$ species (Fig. S4). The oxygenated functional groups can strongly stabilize the newly formed PdAg alloy NPs and largely prevent their overgrowth, allowing them to maintain their ultrafine size on the carbon matrix. Additionally, the dispersion, which represents the fraction of exposed active metal atoms on a catalyst, can be roughly determined using the average size of metal NPs $[23,24]$. Thus, the ultrafine size of the PdAg alloy NPs promoted their high dispersion on the catalyst. This indicates that during the synthetic process, $\mathrm{NaOH}$ either controls the dispersion of PdAg alloy NPs on the carbon matrix. Notably, no post-treatment was applied to the carbon matrix in this work to synthesize the supported PdAg alloy NPs. Thus, it was surmised that other carbon materials, such as conductive carbon black, 3D graphene, super $\mathrm{P}$, and self-prepared 3D porous carbon, could be used as matrices for the NPs. As expected, three $\mathrm{Pd}_{5} \mathrm{Ag}_{5} / \mathrm{C}$ samples were successfully prepared using these carbon materials as the matrix; the PdAg alloy NPs on these matrices had sizes of $4.3,3.6$, and $3.5 \mathrm{~nm}$ and were highly dispersed (Figs. S5-S8). Based on these results, it can reasonably be concluded that the topological structure of the carbon matrix has little influence on the size and distribution of PdAg alloy NPs.

The electrocatalytic HOR and HER in alkaline electrolytes are the subject of extensive investigation, as these reactions are the key steps in alkaline fuel cells and water splitting, respectively. Because of their high intrinsic activities, Pt-based materials are ideal catalysts for both the HOR and HER. However, their practical application has been hindered by the limited availability and high cost of Pt [25-30]. To overcome this problem, the development of various affordable Pt-free catalysts with high performance is of great significance, but remains a challenge. Pd-based materials have been widely reported as substitutes for Pt-free catalysts and have attracted great attention in recent years. Unfortunately, to date, their electrocatalytic activity for the HOR and HER have been far lower than that required for actual applications. Consequently, the HOR and HER were selected as model reactions to explore the electrocatalytic activity of the developed $\mathrm{PdAg} / \mathrm{C}$ catalysts in this work.

First, the HOR electrocatalytic activity of $\mathrm{PdAg} / \mathrm{C}$ samples with a Pd mass loading of $10 \mathrm{ugPd}_{\mathrm{Pm}} \mathrm{cm}^{-2}$ was explored in $0.1 \mathrm{M}$ $\mathrm{KOH}$ solution using a standard three-electrode system at room temperature. As shown in the $i R$-corrected HOR polarization curves collected at different rotation speeds in Figs. S9(a), S10(a), and S11(a), the anodic current increased as the rotation speed was increased from 400 to $1600 \mathrm{rpm}$, indicating that the HOR for these samples was triggered via mass-transfer related anodic current [31]. Importantly, it is the Pd in the alloy samples that determines their HOR activity. Therefore, only the three Pd-enriched samples $\left(\mathrm{Pd} / \mathrm{C}, \mathrm{Pd}_{9} \mathrm{Ag}_{1} / \mathrm{C}\right.$, and $\left.\mathrm{Pd}_{5} \mathrm{Ag}_{5} / \mathrm{C}\right)$ were investigated in this part. Fig. 5(a) shows the $i R$-corrected HOR polarization curves of the three catalysts collected at 1600 rpm. $\mathrm{Pd}_{9} \mathrm{Ag}_{1} / \mathrm{C}$ showed the best HOR activity among these samples, with the largest current density of $0.72 \mathrm{~mA} \mathrm{~cm}^{-2}$ at an overpotential of $100 \mathrm{mV}$ (Fig. 5(b)). This value was obviously higher than that of $\mathrm{Pd}_{5} \mathrm{Ag}_{5} / \mathrm{C}\left(0.25 \mathrm{~mA} \mathrm{~cm}^{-2} @ 100 \mathrm{mV}\right)$ and 

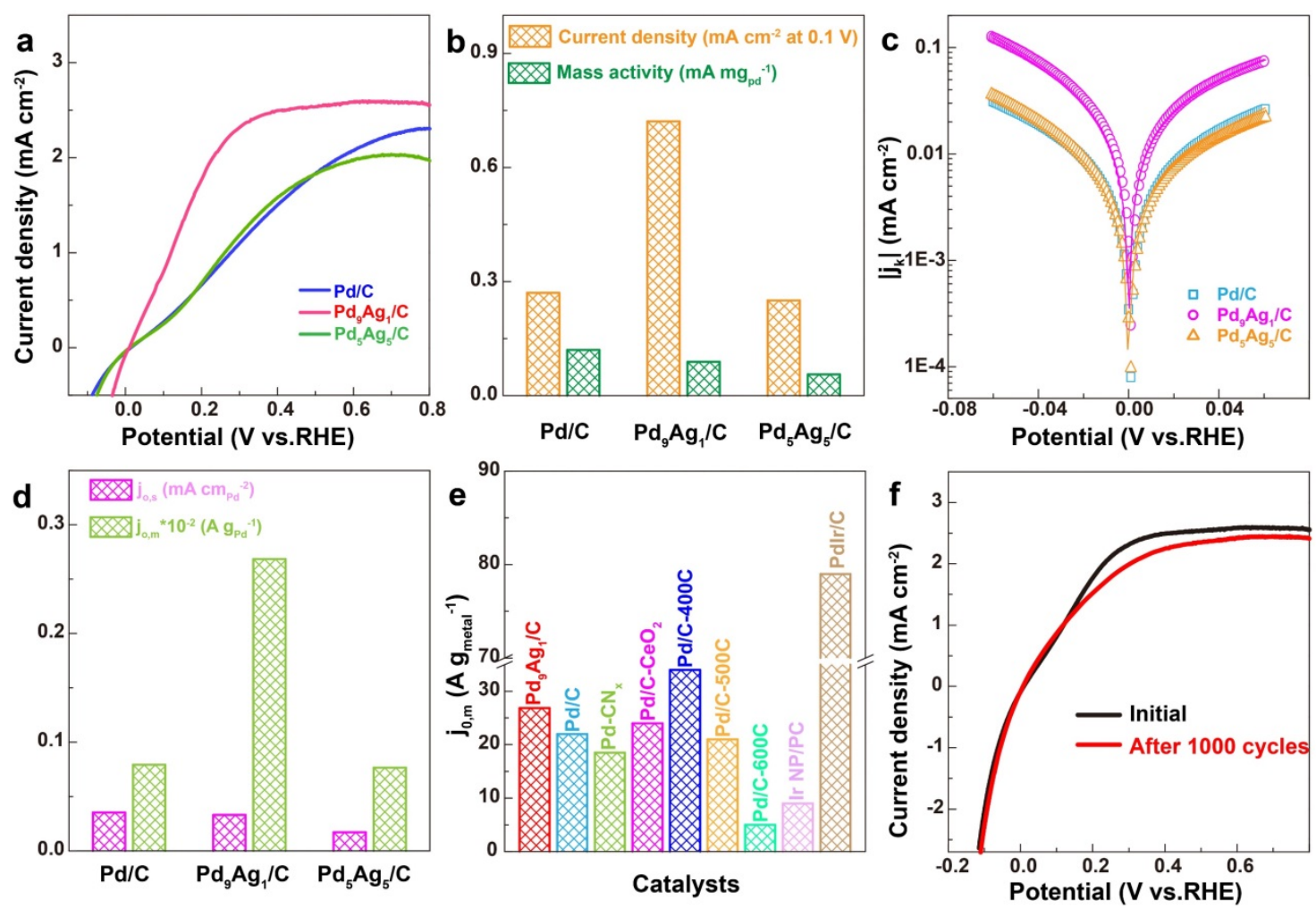

Fig. 5. (a) HOR polarization curves in $\mathrm{H}_{2}$-saturated $0.1 \mathrm{M} \mathrm{KOH}$; (b) Comparison of the current densities and Pd mass activities at an overpotential of $100 \mathrm{mV}$; (c) Tafel plots of the HOR/HER kinetic currents and corresponding fittings with the Butler-Volmer equation; (d) $j_{0, \mathrm{~s}}$ and $j_{0, \mathrm{~m}}$ values for Pd/C, $\mathrm{Pd}_{9} \mathrm{Ag}_{1} / \mathrm{C}$, and $\mathrm{Pd}_{5} \mathrm{Ag}_{5} / \mathrm{C}$; (e) Comparison of the exchange current density $\left(j_{0, \mathrm{~m}}\right.$ and $\left.j_{0,5}\right)$ of $\mathrm{Pd}_{9} \mathrm{Ag}_{1} / \mathrm{C}$ with those of other reported catalysts; (f) Polarization curves of $\mathrm{Pd}_{9} \mathrm{Ag}_{1} / \mathrm{C}$ before and after $1000 \mathrm{CV}$ cycles.

Pd/C (0.27 mA cm-2 @100 mV). For an accurate comparison, the HOR electrocatalytic activity was normalized by the total $\mathrm{Pd}$ mass of the working electrode. As shown in Fig. 5(b), $\mathrm{Pd}_{9} \mathrm{Ag}_{1} / \mathrm{C}$ also exhibited the best mass activity for HOR, with a high mass current density of $0.0887 \mathrm{~mA} \mathrm{mg}^{-1}$ at a low overpotential of $100 \mathrm{mV}$. The distinct activities of these samples were ascribed mainly to the different intrinsic activities of the NPs, which was corroborated by their exchange current density $\left(j_{0}\right)$ normalized by the Pd mass or electrochemical surface area (ECSAs) $(j 0, \mathrm{~s}$ or $j_{0, \mathrm{~m}}$ [32]. The $j_{0}$ was calculated using the Butler-Volmer equation (Eq. (1)) [33],

$$
j_{\mathrm{k}}=j_{0}\left(e \frac{\alpha F}{R T} \eta-e \frac{(\alpha-1) F}{R T} \eta\right)
$$

where $\alpha, j_{\mathrm{k}}, j 0, F, R, T$, and $\eta$ correspond to the transfer coefficient, kinetic current density, exchange current density, Faraday constant (96485 $\mathrm{C} \mathrm{mol}^{-1}$ ), universal gas constant (8.314 J $\left.\mathrm{mol}^{-1} \mathrm{~K}^{-1}\right)$, room temperature $(298 \mathrm{~K})$, and electron number, respectively.

Typically, $j_{k}$ is obtained using the Koutecky-Levich equation (Eq. (2)), as shown in Figs. S9(b),(c), S10(b),(c), and S11(b),(c) [34],

$$
\frac{1}{j}=\frac{1}{j_{\mathrm{k}}}+\frac{1}{j_{\mathrm{d}}}=\frac{1}{j_{\mathrm{k}}}+\frac{1}{B C_{0} \omega^{0.5}}
$$

where $j_{\mathrm{d}}$ is the diffusion limited current, $B$ is the Levich constant, $C_{0}$ is the hydrogen concentration in $0.1 \mathrm{M} \mathrm{KOH}$, and $\omega$ is the rotation speed.

The ECSAs of these samples was calculated based on the ar- eas of the redox peak of Pd in the cyclic voltammetry (CV) curves, which were obtained in Ar-saturated $0.1 \mathrm{M} \mathrm{KOH}$ using a scan rate of $10 \mathrm{mV} \mathrm{s}^{-1}$. The ECSAs of $\mathrm{Pd} / \mathrm{C}, \mathrm{Pd}_{9} \mathrm{Ag}_{1} / \mathrm{C}$, and $\mathrm{Pd}_{5} \mathrm{Ag}_{5} / \mathrm{C}$ were measured to be $22.5,81.3$, and $44.9 \mathrm{~m}^{2} \mathrm{~g}^{-1}$, respectively (Fig. S12 and Table S1).

As shown in Fig. 5(c),(d), $\mathrm{Pd}_{9} \mathrm{Ag}_{1} / \mathrm{C}$ showed the best HOR catalytic activity with the largest $j_{0, \mathrm{~s}}$ of $0.033 \mathrm{~mA} \mathrm{cmPd}-2$ and $j_{0, \mathrm{~m}}$ of $26.5 \mathrm{~A} \mathrm{~g}_{\mathrm{Pd}^{-}}-1$. Taking into account the realistic cost and resource of noble metals, $j_{0, \mathrm{~m}}$ is normally considered more significant than $j_{0, \mathrm{~s}}$ [32]. The $j_{0, \mathrm{~m}}$ value of $\mathrm{Pd}_{9} \mathrm{Ag}_{1} / \mathrm{C}$ was higher than that of most Pd-based materials, including $\mathrm{Pd}-\mathrm{CN}_{x}\left(j_{0, \mathrm{~m}}=18.5 \mathrm{~A}\right.$

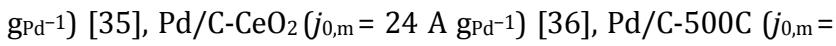
$21 \mathrm{~A} \mathrm{gPd}^{-1}$ ) [37], and Pd/C (jo,m $=22 \mathrm{~A} \mathrm{gPd}^{-1}$ ) [38] (Fig. 5(e) and Table S2). Additionally, the HOR stability of $\mathrm{Pd}_{9} \mathrm{Ag}_{1} / \mathrm{C}$ was further assessed using CV scanning from -0.2 to $1.0 \mathrm{~V}$ at $50 \mathrm{mV} \mathrm{s}^{-1}$ in $\mathrm{H}_{2}$-saturated electrolyte solution (Fig. 5(f)). After the test, the $\mathrm{Pd}_{9} \mathrm{Ag}_{1} / \mathrm{C}$ showed negligible degradation, demonstrating the high stability of $\mathrm{Pd}_{9} \mathrm{Ag}_{1} / \mathrm{C}$ for HOR in an alkaline medium.

Moreover, the electrocatalytic activity of $\mathrm{PdAg} / \mathrm{C}$ with a catalyst loading of $1.39 \times 10^{-3} \mathrm{~g}_{\text {cat. }} \mathrm{cm}^{-2}$ on a rotating disk electrode $(d=3 \mathrm{~mm})$ for the HER in an alkaline medium $(1.0 \mathrm{M} \mathrm{KOH})$ was also explored. As shown in Fig. 6(a), $\mathrm{Pd}_{9} \mathrm{Ag}_{1} / \mathrm{C}$ exhibited the best HER performance among all the catalysts, with the smallest overpotential of $68 \mathrm{mV}$ at a current density of $10 \mathrm{~mA} \mathrm{~cm}-2$; this value was clearly lower than that of $\mathrm{Pd} / \mathrm{C}\left(\eta_{10}=116 \mathrm{mV}\right)$, $\mathrm{Pd}_{5} \mathrm{Ag}_{5} / \mathrm{C}\left(\eta_{10}=90 \mathrm{mV}\right)$, and $\mathrm{Pd}_{1} \mathrm{Ag}_{9} / \mathrm{C}\left(\eta_{10}=241 \mathrm{mV}\right)$. The results suggest that the $\mathrm{Pd}_{9} \mathrm{Ag}_{1} / \mathrm{C}$ with an optimal ratio of $\mathrm{Pd} / \mathrm{Ag}$ 

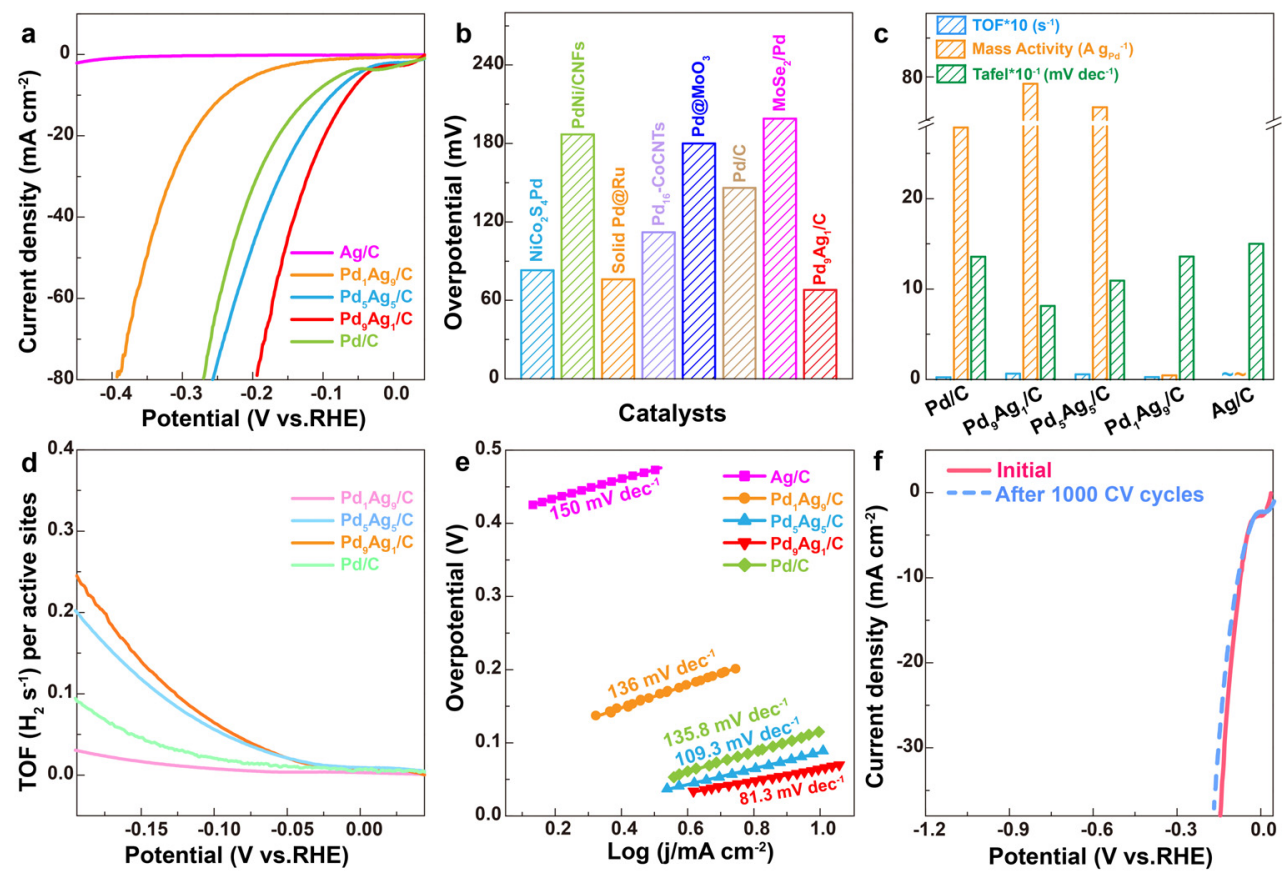

Fig. 6. (a) Polarization curves of $\mathrm{Pd} / \mathrm{C}, \mathrm{Pd}_{9} \mathrm{Ag}_{1} / \mathrm{C}, \mathrm{Pd}_{5} \mathrm{Ag}_{5} / \mathrm{C}, \mathrm{Pd}_{1} \mathrm{Ag}_{9} / \mathrm{C}$ and $\mathrm{Ag} / \mathrm{C}$ in $1.0 \mathrm{M} \mathrm{KOH}$. (b) Comparison of the overpotential (@10 mA cm-2) of $\mathrm{Pd}_{9} \mathrm{Ag}_{1} / \mathrm{C}$ and previous Pd-based nanocatalysts. (c) Comparison of the TOF values, mass activity, and Tafel slopes of all the samples; (d) TOF per surface active site and (e) corresponding Tafel plots. (f) Polarization curves of $\mathrm{Pd}_{9} \mathrm{Ag}_{1} / \mathrm{C}$ before and after $1000 \mathrm{CV}$ cycles.

displays the highest electrocatalytic activity for the HER. Importantly, the HER activity of $\mathrm{Pd}_{9} \mathrm{Ag}_{1} / \mathrm{C}$ was better than that of many recently reported Pd-based electrocatalysts, such as Ni$\mathrm{Co}_{2} \mathrm{~S}_{4} \mathrm{Pd}\left(\eta_{10}=83 \mathrm{mV}\right)$ [39], PdNi/CNFs $\left(\eta_{10}=187 \mathrm{mV}\right)$ [40], and solid Pd@Ru ( $\eta_{10}=76 \mathrm{mV}$ ) [41] (Fig. 6(b) and Table S3). To obtain an exact comparison, the electrocatalytic activity of HER was further normalized by the total Pd mass of the working electrode. As shown in Fig. 6(c), $\mathrm{Pd}_{9} \mathrm{Ag}_{1} / \mathrm{C}$ also presented the largest mass current density (79.4 $\mathrm{A} \mathrm{g}_{\mathrm{Pd}^{-1}}{ }^{-1}$ ) at an overpotential of $100 \mathrm{mV}$. To understand the differences in the electrocatalytic activities of the samples in depth, their TOF and Tafel slopes were assessed. As shown in Fig. 6(c),(d), $\mathrm{Pd}_{9} \mathrm{Ag}_{1} / \mathrm{C}$ exhibited the largest TOF value of $0.0645 \mathrm{~s}^{-1}$ (at an overpotential of 100 $\mathrm{mV}$ ); this value was obviously higher than those of the other samples, indicating the excellent intrinsic activity of $\mathrm{Pd}_{9} \mathrm{Ag}_{1} / \mathrm{C}$ for the HER. Fig. 6(c), and (e) show the Tafel plots of these samples; $\mathrm{Pd}_{9} \mathrm{Ag}_{1} / \mathrm{C}$ showed the lowest Tafel slope of $81.3 \mathrm{mV}$ $\mathrm{dec}^{-1}$, revealing the superior kinetics of $\mathrm{Pd}_{9} \mathrm{Ag}_{1} / \mathrm{C}$ for the HER in an alkaline medium. The HER stability of $\mathrm{Pd}_{9} \mathrm{Ag}_{1} / \mathrm{C}$ was further evaluated using $\mathrm{CV}$ from -0.1 to $0.01 \mathrm{~V}$ with a scan rate of 10 $\mathrm{mV} \mathrm{s}^{-1}$. As shown in Fig. 6(f), negligible change was observed in the HER activity of $\mathrm{Pd}_{9} \mathrm{Ag}_{1} / \mathrm{C}$ before and after $100 \mathrm{CV}$ cycles, indicating the excellent durability of $\mathrm{Pd}_{9} \mathrm{Ag}_{1} / \mathrm{C}$ in an alkaline medium.

The excellent catalytic performance of the $\mathrm{Pd}_{9} \mathrm{Ag}_{1} / \mathrm{C}$ catalyst for HOR/HER is further discussed. First, the TEM images of the $\mathrm{PdAg} / \mathrm{C}$ catalyst revealed that small-sized PdAg alloy NPs were well-distributed on the carbon matrix. This was beneficial, as it increased the fraction of metal atoms with an abundance of unsaturated coordination centers and thus the number of accessible active sites for the HOR/HER [10]. Second, although the different alloy samples exhibited similarly sized PdAg NPs, they were found to have different catalytic activity for the HOR/HER, with $\mathrm{Pd}_{9} \mathrm{Ag}_{1} / \mathrm{C}$ being the best electrocatalyst. This vividly demonstrates that the synergistic and alloy effects of PdAg determine the HOR/HER performance of these catalysts. The absolute value of active hydrogen $\left(\Delta G^{*} \mathrm{H}\right)$ in the HOR/HER is well known to be the key factor for elevating the electrocatalyst. Optimally, $\Delta G^{*}{ }_{\mathrm{H}}$ should be around 0 ; at this value, the surface adsorption of intermediate hydrogen is neither too weak nor too strong. In the literature, the $\Delta G^{*}{ }_{\mathrm{H}}$ of metallic Pd has been reported to be less than zero, whereas that of metallic $\mathrm{Ag}$ is greater than zero [42], i.e., strong spontaneous hydrogen adsorption occurs on metallic Pd, while the adsorption of hydrogen on metallic Ag is difficult. However, it has been reported that the addition of few of $\mathrm{Ag}$ in Pd can induce synergistic and alloy effects that facilitate suitable hydrogen adsorption, and thus enhance the electrocatalytic activity. In the present work, XPS analysis (Figs. S13, 14 and Table S4) revealed that the content of metallic Pd in the three $\mathrm{PdAg} / \mathrm{C}$ samples were similar, suggesting that the strength of the adsorption of $\mathrm{H}$ on $\mathrm{Pd}$ was very similar for the three $\mathrm{PdAg} / \mathrm{C}$ samples, and that the differences in their activities should be ascribed to the different synergistic and alloy effects induced by the amount of metallic Ag. Combined with the electrochemical results, the low content of metallic Ag was found to generate the strongest synergistic and alloy effects for the metallic $\mathrm{Pd}$ in $\mathrm{Pd}_{9} \mathrm{Ag}_{1} / \mathrm{C}$ to give the most facile adsorption-desorption HER/HOR process, and thus, the best catalytic activity. Increasing the content of metallic Ag led to a decrease in the synergistic and alloy; for this reason, $\mathrm{Pd}_{5} \mathrm{Ag}_{5} / \mathrm{C}$ and $\mathrm{Pd}_{1} \mathrm{Ag}_{9} / \mathrm{C}$ exhibited inferior HOR/HER activities. These results suggest that the use of a small amount of metallic Ag is critical for maximizing the synergistic and alloy effects, with $\mathrm{Pd}_{1} \mathrm{Ag}_{9} / \mathrm{C}$ showing excellent electrocatalytic HOR/HER 
activity.

\section{Conclusions}

In this work, a mortar-pestle milling strategy that did not involve the use of any solvents or organic reagents was developed and used to successfully synthesize a series of PdAg alloy NPs with a small size $(4.9 \pm 1.03 \mathrm{~nm})$ and good distribution on a carbon matrix. The composition of the alloy NPs was easily tuned by adjusting the atom ratio of the precursors. The size and distribution of the NPs were not obviously influenced by the topological structure of the carbon matrix. The carbon-supported PdAg alloy NPs acted as efficient electrocatalysts for the HOR/HER in an alkaline medium. $\mathrm{Pd}_{9} \mathrm{Ag}_{1} / \mathrm{C}$ exhibited the highest activity in the HOR, with the largest $j_{0, \mathrm{~m}}$ of 26.5 A $\mathrm{gPd}^{-1}$ and $j_{0, \mathrm{~s}}$ of $0.033 \mathrm{~mA} \mathrm{~cm}_{\mathrm{Pd}^{-}} 2$, as well as in the HER, with the lowest overpotential of $68 \mathrm{mV}$ at $10 \mathrm{~mA} \mathrm{~cm}^{-2}$. The outstanding electrochemical activity was ascribed to the highly distributed small alloy NPs with clean surfaces and thus an abundance of accessible active sites, along with the positive synergistic and alloy effects between the Pd and Ag atoms, which provided excellent intrinsic activity. This study not only provides a scalable, general, and sustainable method to produce supported metal NP catalysts, but also offers a new opportunity to synthesize efficient SMACs for other important reactions.

\section{References}

[1] N. Xiao, S. Li, S. Liu, B. Xu, Y. Li, Y. Gao, L. Ge, G. Lu, Chin. J. Catal., 2019, 40, 352-361.

[2] X. Leng, K.-H. Wu, B.-J. Su, L.-Y. Jang, I. R. Gentle, D.-W. Wang, Chin. J. Catal., 2017, 38, 1021-1027.

[3] P. Xu, Z. Wu, J. Deng, Y. Liu, S. Xie, G. Guo, H. Dai, Chin. J. Catal., 2017, 38, 92-105.

[4] A. K. Singh, Q. Xu, ChemCatChem, 2013, 5, 652-676.

[5] Z. L. Zhao, L. Y. Zhang, S. J. Bao, C. M. Li, Appl. Catal. B, 2015, 174-175, 361-366.

[6] S. Koutsopoulos, R. Barfod, K. M. Eriksen, R. Fehrmann, J. Alloys Compd., 2017, 725, 1210-1216.
[7] Y. Pi, Q. Shao, P. Wang, J. Guo, X. Huang, Adv. Funct. Mater., 2017, $27,1700886$.

[8] J. Wu, G. Gao, J. Li, P. Sun, X. Long, F. Li, Appl. Catal. B, 2017, 203, 227-236.

[9] Y. Yao, Z. Huang, P. Xie, L. Wu, L. Ma, T. Li, Z. Pang, M. Jiao, Z. Liang, J. Gao, Y. He, D. J. Kline, M.R. Zachariah, C. Wang, J. Lu, T. Wu, T. Li, C. Wang, R. Shahbazian-Yassar, L. Hu, Nat. Nanotechnol., 2019, 14, 851-857.

[10] Q. Wang, M. Ming, S. Niu, Y. Zhang, G. Fan, J.-S. Hu, Adv. Energy Mater., 2018, 8, 1801698.

[11] V.-F. Ruiz-Ruiz, R. González-Olvera, R. Díaz-Pardo, I. Betancourt, I. Zumeta-Dubé, D. Díaz, N. Farfán, M. J. Arellano-Jiménez, Materialia, 2018, 4, 166-174.

[12] V.-F. Ruiz-Ruiz, I. Zumeta-Dubé, D. Díaz, M. J. Arellano-Jiménez, M. José-Yacamán, J. Phys. Chem. C, 2017, 121, 940-949.

[13] A. Murugadoss, N. Kai, H. Sakurai, Nanoscale, 2012, 4, 1280-1282.

[14] Y. Ding, W. Sun, W. Yang, Q. Li, Appl. Catal. B, 2017, 203, 372-380.

[15] H. Liu, Y. Guo, Y. Yu, W. Yang, M. Shen, X. Liu, S. Geng, J. Li, C. Yu, Z. Yin, H. Li, J. Mater. Chem. A, 2018, 6, 17323-17328.

[16] L. Shang, F. Zhao, B. Zeng, Electrochim. Acta, 2015, 168, 330-336.

[17] D. Bin, B. Yang, K. Zhang, C. Wang, J. Wang, J. Zhong, Y. Feng, J. Guo, Y. Du, Chem. Eur. J, 2016, 22, 16642-16647.

[18] C. Peng, W. Yang, E. Wu, Y. Ma, Y. Zheng, Y. Nie, H. Zhang, J. Xu, J. Alloys Compd., 2017, 698, 250-258.

[19] J. Zeng, W. Zhang, Y. Yang, D. Li, X. Yu, Q. Gao, ACS Appl. Mater. Interfaces, 2019, 11, 33074-33081.

[20] B. T. X. Lam, M. Chiku, E. Higuchi, H. Inoue, J. Power Sources, 2015, 297, 149-157.

[21] F. Gao, Y. Zhang, P. Song, J. Wang, C. Wang, J. Guo, Y. Du, J. Power Sources, 2019, 418, 186-192.

[22] Q.-L. Zhu, N. Tsumori, Q. Xu, Chem. Sci., 2014, 5, 195-199.

[23] Y. Li, X. Xu, P. Zhang, Y. Gong, H. Li, Y. Wang, RSC Adv., 2013, 3, 10973-10982.

[24] J. Wang, Z. Wei, S. Mao, H. Li, Y. Wang, Energy Environ. Sci., 2018, $11,800-806$

[25] B. Qin, H. Yu, J. Jia, C. Jun, X. Gao, D. Yao, X. Sun, W. Song, B. Yi, Z. Shao, Nanoscale, 2018, 10, 4872-4881.

[26] F. Yang, L. Fu, G. Cheng, S. Chen, W. Luo, J. Mater. Chem. A, 2017, 5, 22959-22963.

[27] N. Ramaswamy, S. Ghoshal, M. K. Bates, Q. Jia, J. Li, S. Mukerjee, Nano Energy, 2017, 41, 765-771.

\section{Graphical Abstract}

Chin. J. Catal., 2021, 42: 251-258 doi: 10.1016/S1872-2067(20)63650-6

Sustainable solid-state synthesis of uniformly distributed PdAg alloy nanoparticles for electrocatalytic hydrogen oxidation and evolution

Caili Xu, Qian Chen, Rong Ding, Shengtian Huang, Yun Zhang *, Guangyin Fan * Sichuan Normal University; Sichuan University of Science and Engineering

A facile grinding strategy is developed to produce a series of PdAg alloy NPs that are highly dispersed on various carbon supports. The resulting electrocatalysts exhibit excellent activities and stabilities in both the HOR and HER.

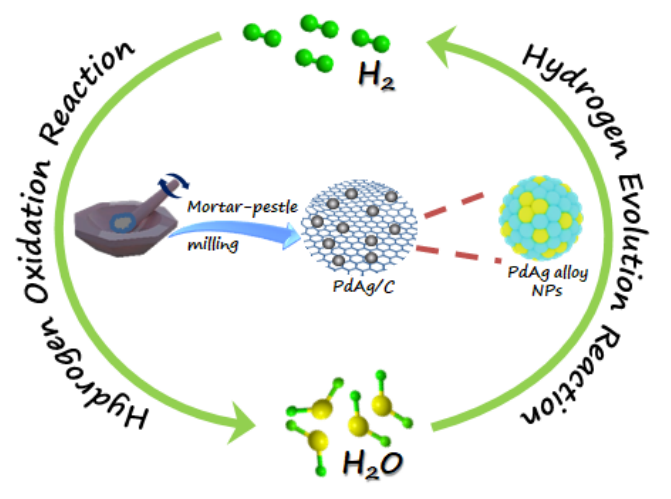


[28] S. Lu, Z. Zhuang, J. Am. Chem. Soc., 2017, 139, 5156-5163.

[29] B. P. Setzler, Z. Zhuang, J. A. Wittkopf, Y. Yan, Nat. Nanotechnol., 2016, 11, 1020-1025.

[30] J.-F. Huang, Y.-C. Wu, ACS Sustainable Chem. Eng., 2018, 6, 8285-8290.

[31] F. Yang, X. Bao, Y. Zhao, X. Wang, G. Cheng, W. Luo, J. Mater. Chem. A, 2019, 7, 10936-10941.

[32] Y. Cong, B. Yi, Y. Song, Nano Energy, 2018, 44, 288-303.

[33] W. Sheng, A. P. Bivens, M. Myint, Z. Zhuang, R. V. Forest, Q. Fang, J. G. Chen, Y. Yan, Energy Environ. Sci., 2014, 7, 1719-1724.

[34] W. Sheng, Z. Zhuang, M. Gao, J. Zheng, J. G. Chen, Y. Yan, Nat. Commun., 2015, 6, 5848.

[35] T. Bhowmik, M. K. Kundu, S. Barman, ACS Catal., 2016, 6, 1929-1941.

[36] H. A. Miller, A. Lavacchi, F. Vizza, M. Marelli, F. Di Benedetto, F.
D'Acapito, Y. Paska, M. Page, D. R. Dekel, Angew. Chem. Int. Ed., 2016, 55, 6004-6007.

[37] J. Zheng, S. Zhou, S. Gu, B. Xu, Y. Yan, J. Electrochem. Soc., 2016, 163, F499-F506.

[38] S. St. John, R. W. Atkinson, R. R. Unocic, T. A. Zawodzinski, A. B. Papandrew, The J. Phys. Chem. C, 2015, 119, 13481-13487.

[39] G. Sheng, J. Chen, Y. Li, H. Ye, Z. Hu, X.-Z. Fu, R. Sun, W. Huang, C.-P. Wong, ACS Appl. Mater. Interfaces, 2018, 10, 22248-22256.

[40] J. Chen, J. Chen, D. Yu, M. Zhang, H. Zhu, M. Du, Electrochim. Acta, 2017, 246, 17-26.

[41] Y. Luo, X. Luo, G. Wu, Z. Li, G. Wang, B. Jiang, Y. Hu, T. Chao, H. Ju, J. Zhu, Z. Zhuang, Y. Wu, X. Hong, Y. Li, ACS Appl. Mater. Interfaces, 2018, 10, 34147-34152.

[42] C. Yang, H. Lei, W. Z. Zhou, J. R. Zeng, Q. B. Zhang, Y. X. Hua, C. Y. Xu, J. Mater. Chem. A, 2018, 6, 14281-14290.

\title{
可持续固相合成高分散PdAg合金纳米颗粒用于电催化氢氧化和氢析出反应
}

\author{
徐才丽 ${ }^{\mathrm{a}}$, 陈 倩 $\mathrm{a}$, 丁 蓉 ${ }^{\mathrm{a}}$, 黄生田 ${ }^{\mathrm{b}}$, 张 云, ${ }^{\mathrm{a},}$, 牀光银, ${ }^{\mathrm{a}, \#}$ \\ $\mathrm{a}$ 四川师范大学化学与材料科学学院, 四川成都610068 \\ ${ }^{b}$ 四川轻化工大学绿色催化四川省高等学校重点实验室, 四川自贡643000
}

\begin{abstract}
摘要: 固相研磨作为一种新型可持续的合成方法, 近年来引起了人们广泛关注, 为负载型金属合金纳米催化剂的制备提供 了新思路. 尽管有关合金催化剂研究取得了系列进展，但现有制备方法大多存在操作步骤复杂、形貌难以控制等问题,严 重制约了合金催化剂的规模化应用. 本文发展了一种可持续化策略，即于室温下在玛瑙研针中直接研磨合成了一系列高 分散在碳载体上的小尺寸 PdAg合金纳米颗粒 $(\mathrm{PdAg} / \mathrm{C})$. 此法无需任何溶剂和有机试剂, 保证了整个过程简单便捷、绿色环 保，同时确保了 PdAg合金纳米颗粒表面清洁无污染，利于样品的催化应用. 利用 TEM, XRD和XPS表征技术对系列 $\mathrm{PdAg} / \mathrm{C}$ 样品的组成及形貌进行了深入探究. TEM结果表明, 所得催化剂中金属颗粒尺寸较小 $(4.9 \pm 1.03 \mathrm{~nm})$, 且高度分散在 碳载体表面. XRD结果表明, $\mathrm{Pd}_{9} \mathrm{Ag}_{1} / \mathrm{C}, \mathrm{Pd}_{5} \mathrm{Ag}_{5} / \mathrm{C}$ 和 $\mathrm{Pd}_{1} \mathrm{Ag}_{9} / \mathrm{C}$ 催化剂特征衍射峰位于对应的 $\mathrm{Pd} / \mathrm{C}$ 和 $\mathrm{Ag} / \mathrm{C}$ 衍射峰之间, 且会随 着 $\mathrm{Ag}$ 含量的不断增加逐渐向低角度偏移. XPS结果表明, 三个催化剂中均存在 $\mathrm{Pd}, \mathrm{Ag}$ 两种元素, 且随着 $\mathrm{Ag}$ 含量的增加, 它 们的 $\mathrm{Pd} 3 d$ 结合能逐渐正移; 而随着 $\mathrm{Pd}$ 含量的不断增加, 三样品的 $\mathrm{Ag} 3 d$ 结合能逐渐负向偏移. 由此可见, 采用可持续固相 合成法成功制得了碳负载的 PdAg合金纳米颗粒. 一系列对比实验表明, PdAg合金纳米颗粒的尺寸和分散度显著依赖于 $\mathrm{NaOH}$, 而与碳载体的形貌、比表面积和类型无明显关系. 将系列 $\mathrm{PdAg} / \mathrm{C}$ 样品用于碱性电催化氢氧化(HOR)和析氢反应 (HER)时, 均展现出高的催化性能. 其中, $\mathrm{Pd}_{9} \mathrm{Ag}_{1} / \mathrm{C}$ 催化性能最佳, 在HOR中, 质量交换电流密度和面积交换电流密度分别 为 $26.5 \mathrm{~A} \mathrm{~g} \mathrm{gd}^{-1}$ 和 $0.033 \mathrm{~mA} \mathrm{~cm} \mathrm{Pd}^{-2}$; 在 $\mathrm{HER}$ 中, 电流密度为 $10 \mathrm{~mA} \mathrm{~cm}$-2时所需过电位仅为 $68 \mathrm{mV}$; 此外, $\mathrm{Pd}_{9} \mathrm{Ag}_{1} / \mathrm{C}$ 催化剂经过 1000 圈CV循环测试后, 催化活性未显著衰减, 对两个目标反应均展现出优异的电化学稳定性. $\mathrm{PdAg} / \mathrm{C}$ 高催化活性主要归 因于两个方面: (1) PdAg合金纳米颗粒表面洁净、尺寸小且分散均匀, 能提供大量可利用的活性位点; (2) Pd与 $\mathrm{Ag}$ 之间强的 协同与合金效应使得催化剂具有最佳的本征活性.
\end{abstract}

关键词: 固相合成; 负载型合金纳米颗粒; 电催化; 氢氧化反应; 氢气析出反应

收稿日期: 2020-03-31. 接受日期: 2020-05-07. 出版日期: 2021-02-05.

*通讯联系人. 电话/传真: (028)84760802; 电子信箱: zhangyun@sicnu.edu.cn

\#通讯联系人. 电子信箱: fanguangyin@sicnu.edu.cn

基金来源：国家自然科学基金(21905187, 21777109); 绿色催化四川省高等学校重点实验室(LZJ1802).

本文的电子版全文由Elsevier出版社在ScienceDirect上出版(http://www.sciencedirect.com/science/journal/18722067). 